\title{
Production Practices, Constraints and Opportunities of Abergelle Goat Breed, Northern Ethiopia
}

\author{
Tewodros Alemu ${ }^{1 *}$, Lijalem Abebaw ${ }^{2}$ and Leuelseged Kassa ${ }^{3}$ \\ ${ }^{1}$ Animal Science Department, College of Agriculture, Wollo University, Dessie, ETHIOPIA \\ ${ }^{2}$ Andassa Livestock Research Center, Bahir Dar, ETHIOPIA \\ ${ }^{3}$ International Food Policy Research Institute (IFPRI), Addis Ababa, ETHIOPIA \\ "Corresponding author: T Alemu; E-mail: teda2010@gmail.com
}

Received: 23 Aug., 2020

Revised: 02 Sept., 2020

Accepted: 10 Sept., 2020

\begin{abstract}
The study was conducted to assess the production practices, constraints and opportunities of Abergelle goat breed. Qualitative and quantitative data were collected through focus group discussion and key informant interview by using tools of participatory rural appraisal. The quantitative data were analyzed using SPSS software and the qualitative data ware narrated. The mainstay of livelihoods of the people of Abergelle district was found highly dependent on production of goats. Two types of goat housing were practiced during dry and wet seasons in the study area. Females were not supposed to herd goats and women were culturally prohibited to consume whole goat milk in the study area. The major supporting institutions in the study area to enhance the productivity of the goat breed were Save the Children (UK), Office of Agriculture and Sekota Dryland Agricultural Research Center. The major constraints faced for the production of Abergelle goat breed were lack of supplementary feed during dry seasons, low level of production, inflexible credit services, shortage of animal health extension workers, lack of transportation facilities, the prevalence of diseases and parasites, shortage of veterinary drugs and equipment. On the other hand, the major opportunities for the production of Abergelle goat breed in the area were availability of adaptable improved forage species, presence of water bodies and the existence of vast communal grazing areas. To improve the production and productivity of Abergelle goat breed in the study area, concerned stakeholders should give an emphasis on the aforementioned major constraints and opportunities.
\end{abstract}

\section{HIGHLIGHTS}

(0) Goat production was major livelihood of the community.

(0 Major constraints were feed shortage, low productivity, lack of transportation, diseases and parasites.

Keywords: Feed, livelihood, small ruminant

The livestock population of Ethiopia is one of the largest in the world. The livestock sector contributes to the country's economy in terms of food, export commodity, draught power, transportation, assets, manure, and other similar benefits. The country goats' population is 21.7 million (CSA, 2011). From the total annual meat production cattle contributes $63 \%$, sheep $25 \%$, and goats $12 \%$. Sheep and goat account $90 \%$ of meat and $92 \%$ skin and hide (FAO, 2004).

There are indigenous goat breeds in the country. Abergelle breed is one of the indigenous found along Tekeze River,
Waghimera Zone, some parts of Alamata Tigray, East Gonder Zone of Amhara Region (Kassahun and Solomon, 2008). The breed is characterized as adaptive and produces under extreme adverse conditions, i.e. survive under low quality and quantity feed, and water shortage that make the breed suitable under traditional production system (Alemayehu, 1994). Wag-Himra Nationality

How to cite this article: Alemu, T., Abebaw, L. and Kassa, L. (2020) Production practices, constraints and opportunities of Abergelle goat breed, Northern Ethiopia. J. Anim. Res., 10(5): 677-684. Source of Support: None; Conflict of Interest: None क्ष 
Administration Zone (WHNA) has 536,539 heads of goat while Abergelle district contribute around 24\% (127,889 heads) of the Waghimera zone goat population found in Abergelle district (WHNA, 2012).

Abergelle district is one of the six districts in Wag-Himra Nationality Administration of ANRS where they have the highest contribution to farmers' livelihood compared to other agricultural enterprises. The district has 261, 544 livestock population of which $48.9 \%$ were goats (AWAO, 2012). Goats are important assets, their products and byproducts like meat, milk, and butter are important source of food. Live goat, butter, and skin sale are important source of income to farmers. They are also important source of manure in the crop-livestock mixed farming system. To some extent, their dung mixed with other biofuels is important source of domestic energy. However, the contribution of goat production to the livelihood of the community is less than expected considering the potential of the goat subsector in the area. This is therefore, essential to assess the production practices, constraints and opportunities of Abergelle goat breed to enhance its contribution to the livelihood of the community.

\section{MATERIALS AND METHODS}

\section{The study area}

Abergelle district is located in Northeastern part of ANRS (Fig. 1). It is bordered by Beyeda (West) and Tselemt (North) districts of North Gondar Zone of ANRS; Sehala (West), Ziqualla (South), and Sekota Zuria (South) districts of WHNA of ANRS; Tigray national regional state (North and East).

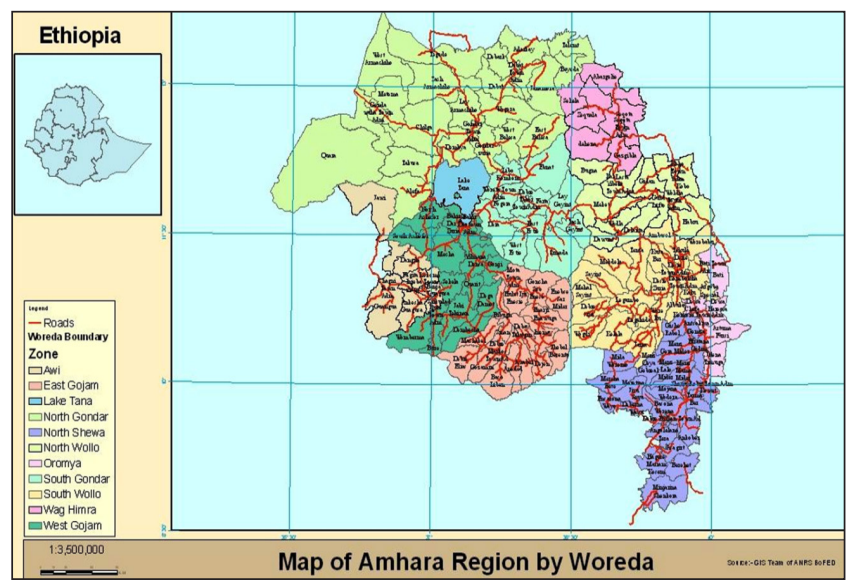

Fig. 1: Map of Amhara region and Abergelle district

\section{Land use classification of Abergelle district}

Abergelle district covers a total area of 166,086 hectares, of which 35,116 hectare of land has a potential for crop production (WHNA, 2012). Currently about 16,364 hectares of land is under cultivation. The district has about 87,601 and 9,895 hectares of grazing and bush lands, respectively. The detailed land use classification of the district is given Table 1. From the table it can be inferred, if appropriate technology is selected, the district has huge potential for livestock feed production.

Table 1: Land use classification of Abergelle district

\begin{tabular}{llll}
\hline Sl. No. & Land use & Area (hectare) & Percentage \\
\hline 1 & Arable land & 16,364 & 9.9 \\
2 & Arable land & 18,752 & 11.3 \\
3 & Forest land & 2,450 & 1.5 \\
4 & Grazing land & 87,610 & 52.7 \\
5 & Bush lands & 9,895 & 6.0 \\
6 & Settlement & 4,113 & 2.5 \\
7 & Bare land & 26,910 & 16.2 \\
\hline 8 & Total & 166,086 & 100 \\
\hline
\end{tabular}

Source: Abergelle district Agriculture office (2012). Arable land = Under cultivation; Arable land $=$ Potential area for cultivation; Bare land $=$ Not used for any purpose

\section{Topography, soil type and water bodies of Abergelle district}

The topography of Abergelle district is $10 \%$ plain, $20 \%$ undulated, $55 \%$ mountainous and $15 \%$ valley which is indicated in Fig. 2 (AWOA, 2012). This shows the limited availability of land for appropriate crop agriculture and the potential for small ruminant production. The soil type is a mixture of sandy and clay. Its color is $55 \%$ brown, $30 \%$ red, and $15 \%$ sandy. The district has rivers like Tekeze and its tributaries like Tirari, Zamra, Tsana, Dina, and Shimsha. These rivers are important source of water for domestic as well as livestock watering. In addition, some of these rivers are also becoming source of water for irrigation. Very recently the Tekeze Hydropower dam has also created an artificial lake. About $90 \%$ of the water body of Tekeze dam lay in the district. The lake is creating a good potential for fishery. 


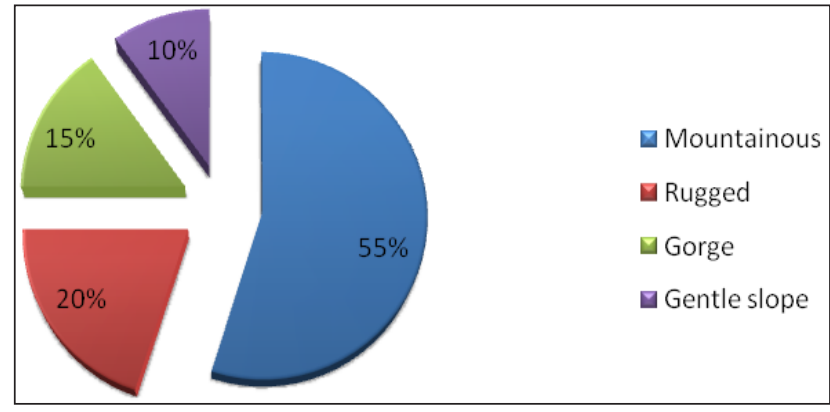

Source: Abergelle district agriculture office

Fig. 2: Topography of Abergele district

\section{Socio-economic characteristics of the study area}

Abergelle district had a total population of 47,106, of which 23,964 were females and 23142 were males (AWOA, 2012). Except few civil servants; nearly all households in the district depend on agriculture for their livelihoods. The farming system can be characterized as crop-livestock mixed dominated by livestock production (Alemu et al., 2015; Alemu et al., 2017; Tewodros Alemu et al., 2013; Belay, 2008). Because the area is characterized by erratic rainfall and the soil has too low fertility to grow enough amounts of food crops even for home consumption. Crop production is restricted to some pocket areas with more fertile soils and moderate moisture (Dereje, 2004).

Currently, Abergelle district has a potential of 35,116.6 hectares for crop agriculture of which 16,364.05 hectare of land is under cultivation. The dominant crops grown in the area were sorghum, sesame, teff, and haricot bean. Farmers also produce honey (Alemu et al., 2015; Alemu et al., 2017; Tewodros Alemu et al., 2013) and rear goats. The crop production is mainly of rain fed. However, now days irrigation agriculture is emerging in some pocket areas along the river banks. For instance, in Saziba, the average holding of irrigable land ranges from 0.125 to 0.375 ha. Farmers majorly produce onion, tomato, and sugar cane using irrigation. This irrigation agriculture helps to diversify household income sources and production of food for home consumption.

Both qualitative and quantitative data were collected from primary and secondary data sources. The qualitative data and/or information include perception and attitude of farmers' about production constraints and opportunities.
The quantitative data includes livestock holding, rainfall distribution and volume of available fodders. The primary data sources were livestock producers, different experts in Abergelle district government offices and agricultural researchers.

Considering the information required, Participatory Rural Appraisal (PRA) technique was employed for data collection. More specifically, Focus Group Discussions (FGD), Key informant Interviews (KII), desk review, and observation/visual appraisal were the methods used for data collection. Checklists, which were prepared for producers and stakeholders of goat production, were used as the main data collection tools. Regarding FGD and KII held and the number of participants; three focus group discussions which had 33 participants and 12 key informant interviews with experts, officials and farmers were held.

\section{Data analysis}

Since most of the data were qualitative in nature and the collection technique was more of informal, descriptive and thematic analysis technique was employed. The quantitative data was analyzed using SPSS software and was presented using tables and graphs. The qualitative data was narrated.

\section{RESULTS AND DISCUSSION}

\section{Dependency on livelihood}

Goat production is the mainstay of livelihoods in the croplivestock mixed farming system of Abergelle district. The FGD discussants in Saziba indicated crop production in the district was challenged by loss of soil fertility, farm size reduction, and recurrent drought and goat production is getting comparative advantage as adaptive/alternative livelihood strategy. Halima et al. (2012) also mentioned that Abergelle breed is adaptive to draught stress. In addition, due to their lower feed requirement than cattle, goat production is becoming the mainstay of the livelihood of rural farm households in the study area (Belay, 2008; Dereje, 2004). Farmers keep Abergelle goat breed for meat and milk production and consumption, source of income to buy food grain during shortages and other miscellaneous household expenses. 
Abergelle district has 261,544 heads of livestock, of which 147,557 are goats and sheep (AWAO, 2012). Goat producers in the district are solely smallholders. According to FGD in Saziba village, the per capita goat holding of poor, medium, and rich farmers in the village was 15-30, 60-80, and 200 heads, respectively.

\section{Feed and feeding}

\section{Feed availability and seasonality}

The farmers did not provide supplementary feeds such as pods collecting from browse trees, household products such as atela (residue of local beer), concentrates and silage. However, during the dearth period they provide sorghum stover for sick and lactating goats.

The FGDs categorized months as very heavy rainfall scored five; medium rainfall scored three; little rainfall scored one and no rain fall scored zero. They showed that rainfall distribution from June to August with the high rainfall record in July (Fig. 3). The highest feed availability was in August. During the months from February to May, feed availability is negligible due to the long dry season. This causes body weight loss and even death of the goats.

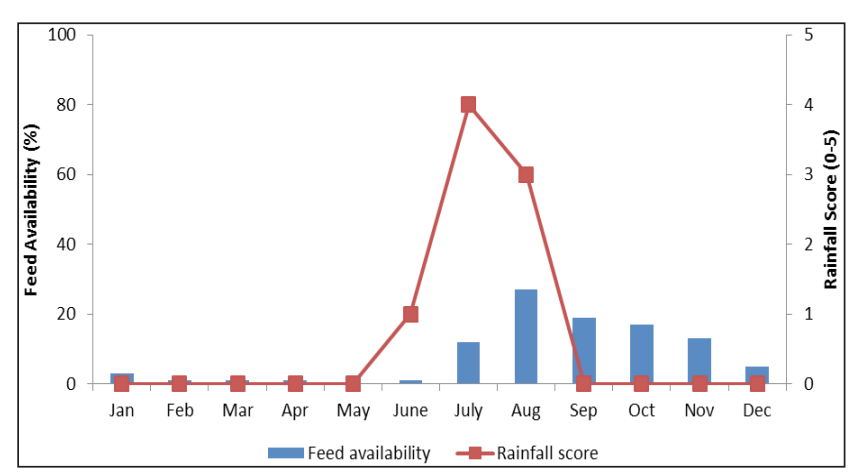

Fig. 3: Feed availability relative to rainfall distribution Source: FGD (2012)

The types of feed availability vary along the seasons. During keremt green fodder accounts, almost $20 \%$ of the feed while $80 \%$ of feed get from browsing (Fig. 4). During first and second bega green fodder would not be longer available for goats rather sorghum stover was available for lactating and sick goats. Nevertheless, other goats could not get supplementary feed during dearth period.

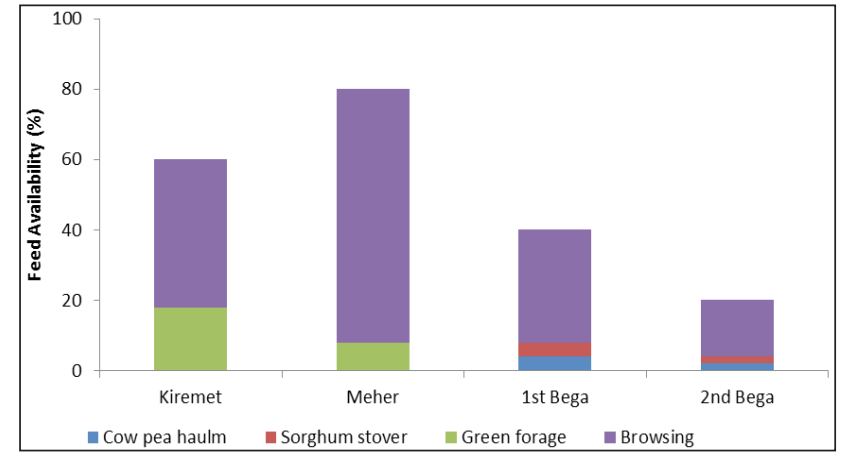

Fig. 4: Seasonal feed resource availability and composition (Source: Focused group discussion, 2012)

\section{Feed shortage coping mechanisms}

Despite sever goat feed shortage in the area, farmers give little emphasis to supplementation of goats. Even though some improved forage species like cowpea, lablab, vetch, oat and elephant grass have been introduced by different development and research organizations (Alemu and Amare, 2016); their utilization as a main or supplementary goat feed remains negligible, This is because of small and fragmented farmland holding size per household (0.7 hectare) (Tewodros, 2010).

However, there are some traditional feed management practices in the area. Seasonal stock movement in search of browses, feeding sorghum stock and haulm of cowpea for kids and old goats, and feeding cuts of tree branches are among the traditional feeding practices used as coping mechanisms during feed shortage seasons. Even though it is declining due to land shortage, there are also rotational grazing/browsing traditions by reserving communal lands along rivers for use in dry seasons. Such temporarily protected areas will be free of grazing from December to January.

The other traditional practice in feeding goats is feeding salty soil during rainy seasons. In July and August, farmers take their goats to those specific areas that have salty soil or bring that salty soil to home and give it to their goats. Farmers believe this will help goats to keep them healthy and get good body condition.

\section{Breeding of Abergelle goats}

Abergelle goat breed is the predominant breed farmers 
of Waghimera Zone in General and Abergelle District in particular are rearing. The experts and farmers believe its merit is drought resistance and adaptation to the unique agro-climatic condition. There is no improved breed introduced to the area. Sekota Dry Land Agricultural Research Center was in the process of crossing Begayet (Barka) and Abergelle breeds to improve meat and milk productivity. Nevertheless, the crossing is already discontinued due to the change of a strategy to conserve and improve the productivity of Abergelle breed through selection before crossing.

The FGDs characterized Abergelle breed as short ear, small body size, drought resistant one that does not lose significant weight while giving birth and milking and live in such special undulated topography. They also stressed the good quality of the Abergelle breed in terms of the special test of its meat.

It was learnt that farmers in the area are selecting better performing animals for breeding stock. The selection criteria differ for male and female goats. They consider physical appearance, color and sexual desire as main criteria to select bucks and prolificacy, milk yield, kidding interval, physical appearance and color to select females. These criteria are evaluated directly on the individual animal to be selected or inferred from its pedigree. Breeding males are used for 3-5 years after which they are sold or castrated.

The farmers keep their flocks individually to protect unwanted mating among different herds. In this situation, goats of similar inheritance mate each other. The farmers do not share and sale bucks to their neighbor for breeding purpose due to the traditional believe that "The farmer will lose his flock if his buck serves another farmer's does"; and also fear disease transmission between flocks. Farmers do not practice formal recording but they know the performance and behavior of each goat in the herd. Therefore, to sustain goat production as the major livelihood strategy, there has to be improvement of the breed either in selection or in crossing with other indigenous or exotic goat breeds.

\section{Animal health care}

Both microbial and parasitic caused diseases are prevalent in the study area. Microbial caused diseases are PPR, goat pox, Orf, Actinomycosis and Pasteurellosis. The parasitic diseases are Menge, Lice, Coenurosis and Moniezia expansa. Abergelle district Agriculture office provides vaccine for PPR, pox, anthrax and Ovine pastuerollosis; acaricide for skin disease such as mange mite and tick. Community Animal Health Workers (CAHWs) were trained in some Kebeles, including Saziba to serve the community in providing preliminary veterinary service.

\section{Housing of Abergelle goats}

Housing is vital to improve production and productivity. It also protect from predators and theft. Farmers construct house to keep goats over night. The house for kids is separate from the flock to milk the does in the morning. The type of house is different in dry and wet seasons. The dry season housing is temporary fence made from tree branches. It is used for some time (e.g. two weeks) and then shifted to other place to protect goats from lice, ticks and other insects and disease.

In summer (rainy season), farmers use caves or construct barn with a roof from locally available materials such as grass and tree branches. Farmers clean the barn every morning to protect potential diseases, prevent foot rot and parasites problem. Farmers said that goat milk yield will decrease unless the barn is clean.

\section{Supporting institutions}

\section{Abergelle district agriculture office}

The development support service is mainly provided at input delivery and production stages and it is delivered by office of agriculture (Lijalem et al., 2017). The office of agriculture provided extension services such as veterinary service and distribute improved forage species such as lablab and cowpea. It also develops business plan for HABP beneficiary households. The office also sometimes assists some farmers in restocking goats in collaboration with donors and NGOs.

\section{Sekota dry land agricultural research centre (SDARC)}

SDARC assisted farmers in terms of introducing adaptive forage species such as cowpea, vetch lablab, oat and elephant grass (Alemu and Amare, 2016). Similarly, 
it tried to improve the breed through village based participatory selection approach. However, these efforts have been constrained by shortage of finance and skilled human resources.

\section{Gender division of labour}

It was common to see differences in the roles and responsibilities of men and women in goat production. For instance, men are expected to be involved in herding goats in remote areas (the main herd). Women are expected to feeding and watering kids around the homestead, milking the goats. Unless the household has shortage of male labor for herding, females are not supposed to herd goats going far distance. This is due to the respects given to females in the society and fear of sexual violence. As a result, those who have male labor shortage in the household hire labor on yearly basis mostly in kind payments (sharing 1 out of 4 newly borne kids to the herder).

\section{Cultural issues}

During the FGD we came to know that any goat producer do not want to share his bucks to other goat producers in the same village or in his/her neighborhood. S/he would rather prefer to sell it to someone else whom $\mathrm{s} / \mathrm{he}$ does not know. The reasons were, first they want to have and maintain their own unique herds for different purposes (for instance, better productivity and social prestige) and second they believe if they sell it in their village, the person who purchased their goat will take their luck/wealth. As a result, they do not want to share their unique goats in their village.

Women in the study area are culturally prohibited to consume whole goat milk (Lijalem et al., 2017). The focus group discussants said it is because of the reason that if the woman drinks goats' milk, she will be strong and she refuses to obey her husband's order. Hence, girls and women are not allowed to drink whole milk.

\section{Constraints for production}

Inadequate animal health worker, shortage of drug, equipment and facilities

There was shortage of animal health extension workers who can serve the farming community through providing veterinary services to their goats in particular and all other animals in general. Animal health posts in the kebeles particular and the district in general are not furnished with adequate equipment and drugs to provide quality veterinary services to goats.

\section{Low efficacy of vaccines}

Though the root cause of the problem needs to be further identified, animal health workers in the area indicated that the efficacy level of vaccines provided to livestock in the area is very low. This could be either because of problems in maintaining cold chains or identification of strains of diseases for which the vaccine is provided.

\section{Lack of transportation facilities for animal health workers to reach farmers}

The animal health workers do not have transport services such as car, motor bicycle and mule used to travel from the health post to kebeles and villages to provide veterinary service. Moreover, the veterinarians do not have transport service used to travel from the district capital to the kebeles.

\section{Inflexible credit system (interest rate, collateral)}

ACSI is the sole credit service institute operating in the area. However, its high interest rate (18\%) is not affordable by smallholder farmers (Lijalem et al., 2017). Moreover, the system needs group collateral to ensure the repayment of loans. The problem with the group collateral is that some of the group members take the loan and leave the area so that other group member should repay the loan. This has created a sense of insecurity among the members of the society to take credit using group collateral.

\section{Shortage of feed during dry seasons and lack of alternative sources}

In the long dry seasons and spring, trees and bushes shade their leaves, which make goats to starve and reduce their body size, become infertile and could cause death of animals. There is no alternative source of feed to rescue the animals during such seasons. Feed marketing including roughages and concentrates (especially industrial by products) is not common in the area. Hence, feed shortage 
constrains Abergelle goat production and the benefit of farmers and other actors along the value chain.

\section{Traditional feeding system}

Goat production in the area is based on browses in the bushes and forests. The farmers do not practice providing supplementary feeds such as concentrates and silage to goats throughout the year. This is because there is no practice of providing supplementary feed to goats. Farmers in the area do not make silage and the limited amount of harvested feed is used for larger animals. They perceive that goats can survive on browses and do not need extra feed any time. This traditional feeding practice has to be changed in order to transform the livelihood of farmers through development of goats' value chain in the area.

\section{High incidence of diseases, internal and external parasites}

The incidence of disease, internal and external parasites caused body loss and death of goats there by produce economic loss to the farmers in particular and to the district and in general.

\section{Low productivity}

Abergelle goat breed is adaptable to the area though its meat and milk productivity is very low. On top of the small body size of the breed, inbreeding problem has negatively affected the majority of the herd in terms of body size and the resulting body condition of goats from the area. The same is true with milk yield. On the other hand, the farmers' livelihood strategy is inclined to goat production than crop production due to recurrent drought and the fragility of agricultural land in the area. Therefore, to sustain goat production as the major livelihood strategy, there has to be improvement of the breed either through selection or in crossing with other indigenous or exotic goat breeds.

\section{Opportunities for the production}

\section{Availability of preferred breed}

During discussions made with agricultural experts and farmers, it has been mentioned the presence of relatively unique Abergelle breeds (ecotypes) in some specific places (e.g. Ambadago and Aresgi villages), which are preferred by the local community for their body size and milk yield is an opportunity for improving production and productivity through selection.

\section{Availability of large area for forage development}

Of the total area of the district potential arable land, bushy, and forest areas take the lion share (87\%). Only $9.9 \%$ is used for arable land and $2.5 \%$ for settlement. This can be used for improved forage development that can resist to moisture stress.

\section{Availability of water}

Water is vital for livestock production for drinking and forage development along irrigation canals. Abergelle district is endowed with water bodies such as rivers (Tirary, Zamera etc.) and Tekezie artificial lake. Hence, it is a potential resource for Abergelle goat production for smallholder farmers.

\section{Availability of adapted forage species}

Understanding the need to introduce improved forage species, SDARC has verified the adaptability of forages like cowpea, lablab, and elephant grass in specific locations of Abergelle district. The availability of such improved forage species can be considered as good opportunity for future interventions in Abergelle goat value chain development.

\section{CONCLUSION}

The mainstay for the livelihoods of the people of Abergelle district was found highly dependent on goat production. Two types of goat housing were practiced by the community of the study area for the dry and wet seasons. The major institutions who involve in different interventions in order to enhance the productivity of Abergelle goats in the study area were Save the Children (UK), Office of Agriculture and SDARC. Females were not supposed to herd goats going far distance those who have male labor shortage in the household hire male laborers. Women in the study area were culturally prohibited to consume whole goat milk. The major constraints faced for the production of Abergelle 
goat breed were lack of supplementary feed during dry seasons, low level of production, inflexible credit services, shortage of animal health extension workers, lack of transportation facilities, the prevalence of diseases and parasites, shortage of veterinary drugs and equipment. On the other hand, the major opportunities for the production of Abergelle goat breed in the area were availability of adaptable improved forage species, presence of water bodies and the existence of vast communal grazing areas. To improve the production and productivity of Abergelle goat breed in the study area, concerned stakeholders should give an emphasis on the aforementioned major constraints and opportunities.

\section{ACKNOWLEDGEMENTS}

We would like to Acknowledge International Center for Agricultural Research in Dry Areas (ICARDA) for its initiation and financial support.

\section{REFERENCES}

Alemu,T. and Amare, B. 2016. Adaptation trial of oat (Avena sativa) varieties in Dehana district, northern Ethiopia. J. Anim. Res., 6(1): 15-20.

Alemu, T. Seifu E. and Bezabih A. 2015. Postharvest handling, opportunities and constraints to honey production in northern Ethiopia. Livest. Res. Rural Dev., 27 (91). http://www.lrrd.org/lrrd27/5/tewo27091.html

Alemu, T. Seifu E. and Bezabih A. 2017. Honeybee production practices in Sekota district, northern Ethiopia. African J. Rural Dev., 2(2): 263-275.

AWAO, 2012. Abergelle district agriculture office annual report (working paper). Abergelle District Agriculture Office, Abergelle, Ethiopia, pp. 34.

Alemayehu, N. 1994. Characterization of indigenous goat types and husbandry practices in Northern Ethiopia. MSc. Thesis, Alemaya University of Agriculture, Alemaya, Ethiopia.
Belay, D. 2008. Growth, reproductive performance and carcass characteristics of Abergelle and central highland goat types under traditional management in Sekota district. MSc. Thesis, Haramaya University, Dire Dawa, Ethiopia.

CSA, 2011. Central statistical agency, livestock sample survey of 2010-2011. Ministry of Finance and Economic Development, Addis Ababa, Ethiopia, pp. 25-29.

Dereje, A. 2004. Preliminary survey of livestock production systems in Ziquala district, Wag-himira zone of Amhara regional state. MSc. Thesis, Haramaya University, Dire Dawa, Ethiopia.

FAO, 2004. Food and agriculture organization of the united nations, livestock sector brief: Ethiopia. Livestock information, sector analysis and policy branch (AGAl), FAO, Rome Italy.

Halima, H.M. Baum B., Rischkowsky and Tibbo M. 2012. Phenotypic characterization of Ethiopian indigenous goat populations. Afri. J. Biotechnol., 11(73): 1383813846.

Lijalem Abebaw, Tewodros Alemu, Leuelseged Kassa, Aynalem Haile and Getachew Legese, 2017. Value chain analysis of Abergelle goat breed, northern Ethiopia. Abyssinia J. Sci. Technol., 2(1): 30-39.

Tewodros A. 2010. Honey bee production practices and honey quality in Sekota district, Wag-himra zone, Ethiopia. The case of Sekota district, MSc thesis, Haramaya University, Haramaya.

Tewodros Alemu, Eyassu Seifu and Amsalu Bezabih, 2013. Physicochemical properties of honey produced in Sekota district, northern Ethiopia. Int. Food Res. J., 20(6): 3061-3067.

WNAZ, 2012. Waghimera nationality administrative zone annual report (working paper). Waghimera nationality administrative zone, Sekota, Ethiopia, pp. 56-58. 